\title{
Spontaneous and induced sister chromatid exchanges and delayed cell proliferation in peripheral lymphocytes of Bowen's disease patients and matched controls of arseniasis-hyperendemic villages in Taiwan
}

\author{
Yi-Hsiang Hsu a, Shuan-Yow Li ${ }^{b}$, Hung-Yi Chiou ${ }^{\text {a }}$, Pi-Ming Yeh ${ }^{\text {b }}$, \\ Jung-Chin Liou ${ }^{b}$, Yu-Mei Hsueh ${ }^{c}$, Shu-Hui Chang ${ }^{\text {a }}$, Chien-Jen Chen ${ }^{\text {a. * }}$ \\ a Institute of Epidemiology, College of Public Health, National Taiwan University, No. I Jen-Ai Road Section 1, Taipei 10018. Taiwan \\ ${ }^{b}$ Cytogenetic Laboratory. Chung Shan Medical and Dental College, Taichung, Taiwan \\ ` Department of Public Health, School of Medicine. Taipei Medical College. Tuipei, Taiwan
}

\begin{abstract}
A total of 15 newly-developed Bowen's disease patients and 34 age-sex-residence-matched controls were recruited from three arseniasis-hyperendemic villages in Taiwan to compare spontaneous and arsenic-induced sister chromatid exchanges (SCEs), proportion of cells with high frequencics of SCEs (HFCs), and replication index (RI) in their peripheral lymphocytes. Arsenic-induced Bowen's disease patients were found to have significantly higher spontaneous SCEs and HFCs and a lower spontaneous RI than in matched controls without or with adjustment for age, gender, cigarette smoking, alcohol drinking, tea drinking. status of major diseases. HBsAg carrier status and arsenic exposure indices through multivariate analysis. Sodium arsenite was found to increase SCEs and HFCs and to decrease RI in a dose-response pattern for both cases and controls. The arsenic-induced decrease in RI was significantly greater in arsenic-induced Bowen's disease patients than in matched controls. The arsenic-induced increases in SCEs and HFCs were also consistently, but not statistically significantly. higher in arsenic-induced Bowen's disease patients than in matched controls at all arsenite treatment levels of 0.5 .1 .0 and $2.0 \mu \mathrm{M}$. The arsenic-induced increase in cytogenetic damages and decrease in cell proliferation among arsenic-induced Bowen's disease patients compared with matched controls may result from their long-term exposure to inorganic arsenic through consumption of high-arsenic artesian well water, elevated individual genetic and acquired susceptibility to arsenic-induced damage, or both.
\end{abstract}

Keywords: Arsenic; Skin cancer; Sister chromatid exchange; Replication index; Susceptibility

\section{Introduction}

Inorganic arsenic has been documented as a human carcinogen of skin and lung [1,2]. Arsenic ap-

\footnotetext{
* Corresponding author. Tel.: +886 (2) 3970800 ext. 8359 ; Fax: + 886 (2) 3511955; e-mail: cjchen@ntumc1.mc.ntu.edu.tw
}

pears in the environment due to both natural occurrence and human activities. Health hazards caused by arsenic-polluted water have repeatedly been observed worldwide, including the southwest coast of Taiwan [3], northern Mexico [4], Antofagasta of Chile [5], Argentina [6], border of Hungary and Romania [7], Xinjiang and Inner Mongolia of China 
[8,9], West Bengal of India [10], and Nakorn Srithammarat Province of southern Thailand [11].

Epidemiological investigations have shown a strong association between arsenic exposure and increased risk of human cancers. Blackfoot disease (BFD) is a unique peripheral vascular disorder in a confined area on the southwest coast of Taiwan. The prevalence of skin cancer in the BFD-endemic area was as high as 10.6 per 1000 , and a dose-response relationship was observed between the prevalence of skin cancer and the arsenic concentration in drinking water [3]. Epidemiological studies carried out in the endemic area have shown an elevaled mortality from cancers of the bladder, kidney, lung and liver. The age-standardized mortality ratios (SMR) were 1100 , 772,320 and 170, respectively, in men, and 2009 . $1119,413,229$, respectively, in women compared with the general population in Taiwan $(S M R=100)$ [12]. A dose-response relationship between the mortality from internal cancers and the arsenic concentration in drinking water has also been well documented [13-17]. The tap water supply system was implemented in the endemic area in early 1960s, and the coverage remained low until the mid-1970s.

In a recent study carried out in the BFD-endemic area, the prevalence of skin cancer remained as high as $6 \%$ among residents aged 30 and above. There was a dose-response relationship between the prevalence of skin cancer and indices of arsenic exposure. including the duration of drinking artesian well water, average arsenic concentration in water and cumulative arsenic exposure [18].

There is insufficient evidence showing arsenic is carcinogenic to experimental animals [1.2]. In vitro studies have shown that arsenic is a clastogen to mammalian cells. Arsenic compounds have been well documented to increase the frequency of sister chromatid exchanges (SCEs) [19-26] and chromosomc aberrations (CAs) $[20.21,27,28]$ in human and rodent cells tested in vitro. The coclastogenicity of arsenic with UV. X-ray and DNA crosslinking agents has also been reported [22-25]. An increase in frequencies of SCEs and CAs among humans exposed to arsenic for a long period of time was observed in some studies $[19,29]$, but not in others [30,31]. The discrepancy may result from the differences in study sample size and control of confounding variables.

Immunodeficient patients were found to have an increased risk of skin cancer and lesions [32]. Delayed proliferation of cultured human lymphocytes has been observed among residents exposed to arsenic $[31,33]$. Sodium arsenite and arsenate inhibit the proliferation [19,24,34] and DNA synthesis [35] of human lymphocytes in vitro.

Despite the implementation of tap water supply system in the BFD-endemic area in Taiwan, an increased risk of skin cancer was still observed among residents in the area. The genetic damage due to previous arsenic exposure seems to remain. However, only a small proportion of residents who had consumed high-arsenic artesian well water were affected with arsenic-induced cancers. Whether the development of skin cancer is related to the individual susceptibility to arsenic-induced clastogenicity remains to be elucidated. This study was carried out to compare spontaneous and arsenic-induced SCEs and cell proliferation of peripheral lymphocytes with or without adjustment for arsenic exposure between skin cancer cases and matched controls selected from the BFD-hyperendemic area.

\section{Materials and methods}

\subsection{Study area}

Three villages including Fuhsin, Hsinming and Homei of Putai Township located on the southwest coast of Taiwan were selected as the study area. BFD was hyperendemic in these villages with a prevalence of 9.6 per 1000 in Fuhsin, 10.3 per 1000 in Hsinming and 13.6 per 1000 in Homei [3]. Residents in the study area had used artesian well water for more than 50 years. Artesian well water in the area was found to have a high arsenic content ranging from 700 to $930 \mathrm{ppb}$ [36]. The tap water supply system in the study area was implemented in early 1970s, but the artesian well water is still used for agriculture and pisciculture.

\subsection{Skin cancer cases and matched controls}

A total of 1081 residents in the study area were recruited for a long-term follow-up study in 1988. All subjects underwent a full body examination of skin lesions including hyperpigmentation, hyperker- 
atosis and skin cancers by dermatologists. Clinically-diagnosed skin cancers were confirmed by biopsy. There were three major pathological types of skin cancer, i.e., squamous cell carcinoma (SCC), basal cell carcinoma (BCC) and intraepidermal carcinoma. The intraepidermal carcinoma included Bowen's disease and type B arsenic keratosis [37].

During the follow-up examination from 1989 to 1995, a total of 21 newly-developed skin cancer patients were identified. All these incident cases were affected with Bowen's disease and received no treatment for the disease. Fifteen of them agreed to participate in this cytogenetic study. Another six of them were affected with Bowen's disease which was diagnosed through clinical examination rather than pathological confirmation. As their disease status was not histologically proved, they were not included in the following study. The frequency distributions of their age, gender, other sociodemographic characteristics, and history of disease were the same as those for another 15 cases. For the comparison, another 34 healthy controls matched with cases on age and sex who were free from skin cancers were randomly selected from matching strata of the study cohort. Neither arsenic-induced Bowen's disease cases nor matched controls were affected with BFD or internal cancers. They had received no medical treatments such as medical $\mathrm{X}$-ray irradiation, chemotherapy, and blood transfusion within the last 6 months before the biospecimens were taken.

\subsection{Questionnaire interview}

Standardized personal interview based on a structured questionnaire was carried out at recruitment to obtain information on sociodemographic characteristics, residential and occupational history, life-style variables including alcohol drinking, tea drinking, dietary habits and cigarette smoking, personal and family history of major diseases, history of medical treatment, and history of drinking artesian well water. Detailed residential history and duration of drinking artesian well water were used to derive cumulative arsenic exposure and average arsenic concentration from drinking artesian well water for each study subject. The median arsenic level in artesian well water of each village where study subjects had lived was derived from a previous study [36]. The arsenic level in artesian well water was reported to be reasonably constant in two surveys carried out by Taiwan Provincial Institute of Environmental Sanitation [38]. The cumulative arsenic exposure in ppmyear for each study subject was calculated as the sum of the products, derived by multiplying the arsenic concentration in artesian well water (ppm) by the duration of drinking artesian well water (year) during consecutive periods of living in different villages, i.e.,

$\sum\left(\mathrm{M}_{i} \times \mathrm{D}_{i}\right)$

where $\mathrm{M} i$ was the median arsenic concentration in artesian well water of the village where a given study subject lived during the period $i$, and $\mathrm{D} i$ was the duration of drinking artesian well water in the village during the same period $i$. The average arsenic concentration in drinking water was derived by the formula:

$\frac{\Sigma\left(\mathrm{M}_{i} \times \mathrm{D}_{i}\right)}{\Sigma \mathrm{D}_{i}}$

The duration of living in the BFD-endemic area was calculated as the sum of years living in villages where the prevalence of BFD was greater than zero.

\subsection{Biospecimen collection and laboratory proce- dures}

Heparinized whole blood samples were collected from study subjects for lymphocyte culture, while fasting non-heparinized blood samples wcre collected for the examination of hepatitis $B$ surface antigen (HBsAg), antibody against hepatitis $\mathrm{C}$ virus (anti-HCV), alanine transaminase (ALT), and aspartate transaminase (AST).

Lymphocytes in $0.5 \mathrm{ml}$ heparinized peripheral blood were cultured in $84 \%$ RPMI-1640 medium supplemented with $15 \%$ fetal calf serum, $1 \%$ penicillin/streptomycin/neomycin mixture, and $2 \%$ phytohemagglutinin-M (PHA, Gibco, NY). For the examination of arsenic effect, sodium arsenite $\left(\mathrm{NaAsO}_{2}\right.$, Merck, Darmstadt, Germany) was added at the beginning of cell culture. The final concentrations of sodium arsenite in the culture were $0,0.5$, 1.0 and $2.0 \mu \mathrm{M}$, respectively. After cells were cultured in $\mathrm{CO}_{2}(5 \%)$ incubator at $37^{\circ} \mathrm{C}$ for $24 \mathrm{~h}, 20$ 
$\mu \mathrm{M}$ bromodeoxyuridine (BrdU, Sigma, St. Louis, $\mathrm{MO})$ was added. All cultures containing BrdU were kept in the dark to avoid photolysis of BrdU-containing DNA. Cultured lymphocytes were harvested after $64 \mathrm{~h}$. During the last half hour, cells were treated with $0.1 \mu \mathrm{M}$ colcemid (Gibco Laboratories, New York) to accumulate mitoses prior to the harvest. The harlequin-stained chromosomes were produced by fluorescence plus Giemsa technique [39].

SCEs of peripheral lymphocytes for each subject were microscopically examined. Photographs of at least 40 second metaphases including 43-46 chromosomes were taken, and SCEs were counted on pictures. All SCEs were scored by one person blindly. SCEs at centromeric regions were included only when they were clearly not twisting over. Data are presented as the number of SCE per cell. Metaphases containing chromosomes with both sister chromatids stained uniformly darkly were scored as the first metaphases $\left(\mathrm{M}_{1}\right)$. Those with one sister chromatid stained lightly and the other darkly were scored as the second metaphases $\left(M_{2}\right)$. Metaphases in which some chromosomes with both sister chromatid stained uniformly lightly were scored as the third metaphases $\left(\mathrm{M}_{3}\right)$. Replication index (RI) was scored on 100 consecutive mitoses and calculated as $\left(1 \times \mathrm{M}_{1}+2\right.$ $\left.\times \mathrm{M}_{2}+3 \times \mathrm{M}_{3}\right) / 100$. The value of SCEs/cell corresponding to the 95 th percentile of the pooled data from the arsenic-untreated lymphocytes healthy controls was used as the cutoff value for the definition of high frequency cells (HFCs). HFC data are presented as the percentage of HFCs among scored metaphases [40].

\subsection{Data analysis and statistical method}

The differences in distribution of risk factors between arsenic-induced skin cancer patients and matched healthy controls were tested for statistical significance by chi-square test for categorical variables and Student's $t$-test for continuous variables. SCEs, HFCs and RI for arsenic-induced skin cancer patients and matched healthy controls were compared and tested for statistical significance of the differences by Wilcoxon's rank-sum test. The differences in SCEs, HFCs and RI between arsenic-treated and untreated lymphocytes were tested for statistical significance by paired Wilcoxon's sign-rank test.
Table 1

Comparison of categorical risk factors between arsenic-induced Bowen's disease skin cancer patients and matched controls

\begin{tabular}{|c|c|c|c|}
\hline Variable & No. of cases $(\%)$ & No. of controls $(\%)$ & Odds ratio \\
\hline \multicolumn{4}{|l|}{ Sex } \\
\hline Women & $3(20.0)$ & $9(26.5)$ & 1.0 \\
\hline Men & $12(80.0)$ & $25(73.5)$ & 1.4 \\
\hline \multicolumn{4}{|c|}{ Skin hyperpigmentation and hyperkeratosis } \\
\hline Neither & $2(13.3)$ & $24(70.6)$ & 1.0 \\
\hline Either & $6(40.0)$ & $8(23.5)$ & $9.0^{*}$ \\
\hline Both & $7(46.7)$ & $2(5.9)$ & $42.0 * *$ \\
\hline \multicolumn{4}{|c|}{ Consumption of dried sweet potato chips } \\
\hline No & $0(0.0)$ & $8(23.5)$ & 1.0 \\
\hline Yes & $15(100.0)$ & $26(76.5)$ & 9.2 \\
\hline \multicolumn{4}{|c|}{$\begin{array}{l}\text { Family history of malignant neoplasms } \\
\text { All cancers }\end{array}$} \\
\hline No & $7(46.7)$ & $27(79.4)$ & 1.0 \\
\hline Yes & $8(53.3)$ & $7(20.6)$ & $4.4^{*}$ \\
\hline \multicolumn{4}{|c|}{ Internal cancers } \\
\hline No & $8(53.3)$ & $27(79.4)$ & 1.0 \\
\hline Yes & $7(46.7)$ & $7(20.6)$ & $3.4^{*}$ \\
\hline \multicolumn{4}{|c|}{ Arsenic-induced skin cancers } \\
\hline No & $13(86.7)$ & $34(100.0)$ & 1.0 \\
\hline Yes & $2(13.3)$ & $0(0.0)$ & $10.4^{*}$ \\
\hline
\end{tabular}

" $p<0.05,{ }^{*} p<0.01$ based on the chi-square test for the difference between arsenic-induced skin cancer patients and matched controls.

Multivariate analyses were used to adjust possible confounding effects of age, gender, life-style characteristics, status of major diseases and HBsAg carrier status on SCEs, HFCs and RI. As the data for various arsenic treatment concentrations were repeated measurements, Generalized Estimating Equation (GEE) models were used in the multivariate analysis [41]. Multiple regression analysis was used for the analysis of SCE data, and the square root of SCE was used as the independent variable in GEE model. Multiple linear regression was used for the data analysis of HFCs and RI in GEE models.

\section{Results}

As shown in Table 1, arsenic-induced Bowen's disease patients and matched controls had a similar gender distribution. Cancer patients had a signifi- 
Table 2

Comparison of age and arsenic exposure indices between arsenic-induced Bowen's disease patients and matched controls

\begin{tabular}{lcc}
\hline Variable & Cases (mean \pm SD) & Controis (mean \pm SD) \\
\hline Age & $58.7 \pm 5.5$ & $58.5 \pm 8.6$ \\
Duration of living in BFD-endemic area (years) & $52.5 \pm 5.7$ & $49.0 \pm 13.6^{*}$ \\
Duration of drinking artesian well water (years) & $29.2 \pm 10.2$ & $21.4 \pm 13.1^{*}$ \\
Average arsenic content in artesian well water (ppm) & $0.73 \pm 0.1$ & $0.62^{*} \pm 0.3^{* *}$ \\
Cumulative arsenic exposure (ppm-years) & $21.1 \pm 8.4$ & $14.5 \pm 9.4^{*}$ \\
\hline
\end{tabular}

${ }^{*} p<0.05{ }^{*}{ }^{*} 0.05<p<0.10$ based on Student's $t$-test between arsenic-induced Bowen's disease patients and matched controls.

cantly higher proportion of being affected with skin hyperpigmentation and/or hyperkeratosis than matched controls. The proportion of consumption of dried sweet potato chips was significantly higher among arsenic-induced Bowen's disease skin cancer patients than matched controls. Cancer patients also had a higher frequency of family cancer history than matched controls. The mean age was similar in Bowen's disease patients and matched controls. Cases had a significantly longer duration of living in the BFD-endemic area and consuming artesian well water than matched controls. Both cumulative arsenic exposure and average arsenic content in artesian well water for arsenic-induced Bowen's disease patients were greater than those for matched controls (Table 2).
Arsenic-induced Bowen's disease patients had a significantly lower prevalence of smoking cigarettes (currently $6.7 \%$ ) than matched controls $(41.2 \%$ ), and a significantly higher prevalence of consuming fermented soy beans $(46.7 \%)$ than matched controls (17.6\%). Cases and controls had similar frequency distributions in alcohol drinking, tea drinking, passive smoking, dietary habits, sunlight exposure at work, personal history of diseases including hypertension, diabetes and stroke, as well as history of medical treatment. The seropositivity of HBsAg and anti-HCV and the serum level of AST and ALT were sinilar in the Bowen's disease patients and matched controls.

Spontaneous and arsenite-induced SCEs are shown in Table 3. Arsenic-induced patients had signifi-

Table 3

Spontaneous and arsenite-induced sister chromatid exchanges (SCEs) of peripheral lymphocytes for arsenic-induced Bowen`s disease patients and matched controls

\begin{tabular}{|c|c|c|c|c|c|}
\hline Subjects & $\begin{array}{l}\mathrm{NaAsO}_{2} \\
(\mu \mathrm{M})\end{array}$ & $\begin{array}{l}\text { SCEs / cell } \\
(\text { mean } \pm \text { SE })\end{array}$ & $\begin{array}{l}\Delta \text { SCEs } / \text { cell } \\
(\text { mean } \pm S E)\end{array}$ & $\begin{array}{l}\Delta S C E s / \text { cell } \\
(\text { mean } \pm S E)\end{array}$ & $\begin{array}{l}\Delta \mathrm{SCEs} / \text { cell } \\
(\text { mean } \pm \mathrm{SE})\end{array}$ \\
\hline \multirow{4}{*}{$\begin{array}{l}\text { Arsenic-induced Bowen's } \\
\text { disease patients }\end{array}$} & 0 & $8.42 \pm 0.51^{a}$ & referent & & \\
\hline & 0.5 & $9.71 \pm 0.90^{b}$ & $1.16 \pm 0.44^{e, *}$ & referent & \\
\hline & 1.0 & $10.97 \pm 1.20^{\circ}$ & $2.39 \pm 0.88^{f+}$ & $1.20 \pm 0.68^{*}$ & referent \\
\hline & 2.0 & $11.48 \pm 1.29^{\mathrm{d}}$ & $2.90 \pm 0.92$ & $1.71 \pm 0.72^{* *}$ & $0.52 \pm 0.82^{n}$ \\
\hline \multirow[t]{4}{*}{ Matched controls } & 0 & $6.94 \pm 0.37^{a}$ & referent & & \\
\hline & 0.5 & $7.65 \pm 0.42$ & $0.71 \pm 0.29^{e, *}$ & referent & \\
\hline & 1.0 & $8.58 \pm 0.60^{c}$ & $1.64 \pm 0.54$ f.** & $0.93+0.43^{*}$ & referent \\
\hline & 2.0 & $8.89 \pm 0.61^{d}$ & $2.00 \pm 0.56 \mathrm{~g} * * *$ & $1.24 \pm 0.52^{* *}$ & $0.31 \pm 0.31^{*}$ \\
\hline
\end{tabular}

$\triangle$ SCEs indicate the difference calculated by subtracting the non-induced value (referent) from the induced value of the same individual. a.b.c.d $p<0.05$ based on Wilcoxon's rank-sum test for the difference in spontaneous or arsenite-induced SCEs between cases and controls. e,f,g Statistically non-significant based on Wilcoxon's rank-sum test for the difference in $\triangle$ SCEs between cases and controls.

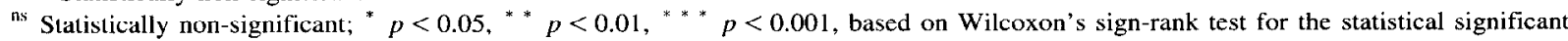
of $\triangle$ SCEs, i.e., the increase in SCEs at a given arsenite concentration compared with referent. 
cantly higher spontaneous SCEs than matched controls ( $p<0.05$ based on non-parametric Wilcoxon's rank-sum test). Arsenite-induced SCEs at the arsenic concentrations of $0.5,1.0$ and $2.0 \mu \mathrm{M}$ were also significantly higher in arsenic-induced Bowen's disease patients than matched controls. There was a dose-response relationship between SCEs and arsenite concentration for both arsenite-induced Bowen's disease patients and matched controls. The increases in arsenite-induced SCEs ( $\triangle$ SCEs) indicated the difference calculated by subtracting the non-induced value (referent) from the induced value of the same individual. The $\triangle$ SCEs at all treatment levels were consistently, but not statistically significantly, greater in arsenic-induced Bowen's disease patients than in matched controls. The $\triangle \mathrm{SCEs}$ at arsenite concentrations of $0.5,1.0$ and $2.0 \mu \mathrm{M}$ comparing with $0 \mu \mathrm{M}$ group as the referent were statistically significant for both cases and controls. The $\triangle$ SCEs at arsenite concentration of 1.0 and $2.0 \mu \mathrm{M}$ comparing with 0.5 $\mu \mathrm{M}$ group as the referent were also statistically significant for both cases and controls. But the $\triangle$ SCEs between 2.0 and $1.0 \mu \mathrm{M}$ groups was statistically significant for controls but not for cases.

The cutoff value for the definition of HFCs of SCEs was 13 SCEs per cell. The frequency distributions of the proportion of cells with high frequency
Table 4

The frequency distributions of the proportion of cells with highfrequency of SCEs (HFCs) for arsenic-induced Bowen's disease patients and matched controls

\begin{tabular}{llllr}
\hline Subjects & $\mathrm{NaAsO}_{2}(\mu \mathrm{M})$ & $<10 \%$ & $10-19 \%$ & $\geq 20 \%$ \\
\hline Matched controls & 0 & $67.7 \%$ & $23.5 \%$ & $8.8 \%$ \\
& 0.5 & $58.9 \%$ & $17.6 \%$ & $23.5 \%$ \\
& 1.0 & $41.2 \%$ & $17.6 \%$ & $41.2 \%$ \\
& 2.0 & $41.2 \%$ & $17.6 \%$ & $41.2 \%$ \\
Arsenic-induced & 0 & $26.7 \%$ & $53.3 \%$ & $20.0 \%$ \\
Bowen's disease & & & & \\
patients & & & & \\
& 0.5 & $26.7 \%$ & $20.0 \%$ & $53.3 \%$ \\
& 1.0 & $20.0 \%$ & $20.0 \%$ & $60.0 \%$ \\
& 2.0 & $20.0 \%$ & $26.7 \%$ & $53.3 \%$ \\
\hline
\end{tabular}

of SCEs (HFCs) for arsenic-induced Bowen's disease patients and matched controls are shown in Table 4. The percentages of spontaneous HFCs lower than $10 \%$ was $67.7 \%$ in matched controls, but only $26.7 \%$ in cases. The higher the arsenite level, the greater the percentage of induced HFCs greater than $10 \%$. As shown in Table 5, arsenic-induced Bowen's disease patients had a significantly higher percentage of spontaneous HFCs $(17.9 \%)$ than matched controls $(8.6 \%)$. The percentages of HFCs at arsenite concentrations of $0.5,1.0$ and $2.0 \mu \mathrm{M}$ were $21.8 \%, 31.0 \%$

Table 5

Spontaneous and arsenite-induced proportion of cells with high-frequency of SCEs (HFCs) of peripheral lymphocytes for arsenic-induced Bowen's disease patients and matched controls

\begin{tabular}{|c|c|c|c|c|c|}
\hline Subjects & $\begin{array}{l}\mathrm{NaAsO}_{2} \\
(\mu \mathrm{M})\end{array}$ & $\begin{array}{l}\text { HFCs } \\
(\text { mean } \pm S E)\end{array}$ & $\begin{array}{l}\triangle \mathrm{HFCs} \\
(\text { mean } \pm \mathrm{SE})\end{array}$ & $\begin{array}{l}\triangle \mathrm{HFCs} \\
(\text { mean } \pm \mathrm{SE})\end{array}$ & $\begin{array}{l}\triangle \mathrm{HFCs} \\
(\text { mean } \pm \mathrm{SE})\end{array}$ \\
\hline \multirow{4}{*}{$\begin{array}{l}\text { Arsenic-induced Bowen`s } \\
\text { disease patients }\end{array}$} & 0 & $17.89 \pm 2.83$ & referent & & \\
\hline & 0.5 & $21.75 \pm 5.29^{b}$ & $2.94 \pm 3.39$ e.n & referent & \\
\hline & 1.0 & $30.98 \pm 6.37^{\circ}$ & $10.79 \pm 4.46^{f, *}$ & $7.80 \pm 3.27 \mathrm{~ms}$ & referent \\
\hline & 2.0 & $31.98 \pm 7.13^{d}$ & $11.75 \pm 5.75 \mathrm{~g}$. & $8.75 \pm 4.24^{*}$ & $0.96 \pm 4.76$ \\
\hline \multirow[t]{4}{*}{ Matched controls } & 0 & $8.59 \pm 1.66^{a}$ & referent & & \\
\hline & 0.5 & $11.00 \pm 2.41^{\mathrm{b}}$ & $2.41 \pm 1.50^{e, n}$ & referent & \\
\hline & 1.0 & $16.44 \pm 3.13^{\circ}$ & $7.85 \pm 2.77^{\mathrm{f}, * *}$ & $5.44 \pm 3.02^{\mathrm{ns}}$ & referent \\
\hline & 2.0 & $18.75 \pm 3.71^{d}$ & $10.26+3.37 \mathrm{~g}, * *$ & $7.75 \pm 3.49^{*}$ & $2.31 \pm 2.08 \mathrm{~ns}$ \\
\hline
\end{tabular}

$\triangle$ HFCs indicate the difference calculated by subtracting the non-induced value (referent) from the induced value of the same individual. ${ }^{\mathrm{a}} p<0.01,{ }^{\mathrm{b}, \mathrm{c}} p<0.05,{ }^{\mathrm{d}} 0.05<p<0.09$ based on Wilcoxon's rank-sum test for the difference in spontaneous or arsenite-induced HFCs between cases and controls.

e.f,g Statistically non-significant based on Wilcoxon's rank-sum test for the difference in $\triangle$ HFCs between cases and controls.

ns Statistically non-significant, ${ }^{*} p<0.05,{ }^{*}{ }^{*} p<0.01,{ }^{* *} p<0.001$, based on Wilcoxon's sign-rank test for the statistical significance of $\triangle \mathrm{HFCs}$, i.e., the increase in HFCs at a given arsenite concentration compared with referent. 
Table 6

Spontaneous and arsenite-induced replication index (RI) of peripheral lymphocytes for arsenic-induced Bowen's disease patients and matched controls

\begin{tabular}{|c|c|c|c|c|c|}
\hline Subjects & $\begin{array}{l}\mathrm{NaAsO}_{2} \\
(\mu \mathrm{M})\end{array}$ & $\begin{array}{l}\text { RI } \\
(\text { mean } \pm S E)\end{array}$ & $\begin{array}{l}\Delta \mathrm{RI} \\
(\text { mean } \pm \mathrm{SE})\end{array}$ & $\begin{array}{l}\Delta \mathrm{RI} \\
(\text { mean } \pm \mathrm{SE})\end{array}$ & $\begin{array}{l}\Delta \mathrm{RI} \\
(\text { mean } \pm S E)\end{array}$ \\
\hline \multirow{4}{*}{$\begin{array}{l}\text { Arsenic-induced Bowen's } \\
\text { disease patients }\end{array}$} & 0 & $2.08 \pm 0.04^{a}$ & referent & & \\
\hline & 0.5 & $1.98 \pm 0.04^{b}$ & $-0.098 \pm 0.029^{\mathrm{e} * *}$ & referent & \\
\hline & 1.0 & $1.84 \pm 0.05^{c}$ & $-0.243 \pm 0.059$ f.** & $-0.145 \pm 0.043^{* * *}$ & referent \\
\hline & 2.0 & $1.81 \pm 0.07^{\mathrm{d}}$ & $-0.269 \pm 0.058^{g . * * *}$ & $-0.171 \pm 0.050^{* *}$ & $-0.026 \pm 0.042^{n s}$ \\
\hline \multirow[t]{4}{*}{ Matched controls } & 0 & $2.24 \pm 0.04^{\mathrm{a}}$ & referent & & \\
\hline & 0.5 & $2.22 \pm 0.04^{b}$ & $-0.021 \pm 0.026^{\mathrm{e} . n s}$ & referent & \\
\hline & 1.0 & $2.15 \pm 0.04^{\circ}$ & $-0.090 \pm 0.022^{f, * * *}$ & $-0.068 \pm 0.016^{* * *}$ & referent \\
\hline & 2.0 & $2.11 \pm 0.04^{d}$ & $-0.131 \pm 0.020 \mathrm{~g} * * *$ & $-0.123 \pm 0.022 * * *$ & $-0.052 \pm 0.020^{\circ}$ \\
\hline
\end{tabular}

$\Delta R I$ indicate the difference calculated by subtracting the non-induced value (referent) from the induced value of the same individual.

${ }^{a, b} p<0.01,{ }^{c, d} p<0.001$ based on Wilcoxon's rank-sum test for the difference in spontaneous and arsenite-induced RI between cases and controls.

e.f.g $p<0.05$ based on Wilcoxon's rank-sum test for the difference in $\Delta$ RI between cases and controls.

ns Statistically non-significant. ${ }^{*} p<0.05,{ }^{* *} p<0.01,{ }^{* * *} p<0.001$. based on Wilcoxon's sign-rank test for the statistical significance of $\Delta$ RI, i.e., the decrease in RI at a given arsenite concentration compared with referent.

and $32.0 \%$, respectively, for arsenic-induced Bowen's disease patients which were significantly higher than corresponding figures for matched controls $(11.0 \%$, $16.4 \%$ and $18.8 \%$ ). Arsenite treatment did significantly increase the percentage of HFCs in both cases and controls. There were consistently, but not statistically significant, higher arsenite-induced $\Delta$ HFCs in cases than in controls at various treatment levels. The HFCs results were quite the same as those for SCEs.
Spontaneous and arsenite-induced RIs are presented in Table 6. Arsenic-induced Bowen's disease patients had significantly lower RIs at arsenite concentrations of $0,0.5,1.0$ and $2.0 \mu \mathrm{M}$ than matched controls. There was a reverse dose-response relationship between RI and arsenite concentration for both cases and controls. The decreases in arsenite-induced RI $(\Delta R I)$ at various treatment levels were statistically significant for both cases and controls, except for the decrease in RI resulting from the

Table 7

Multiple regression of SCEs of arsenic-induced Bowen's disease patients and matched controls induced by sodium arsenite in GEE model

\begin{tabular}{|c|c|c|c|c|c|}
\hline Subjects & $\mathrm{NaAsO}_{2}(\mu \mathrm{M})$ & $\triangle$ SCEs $^{\prime}$ & $95 \% \mathrm{CI}$ & $\triangle$ SCES $^{\circ}$ & $95 \% \mathrm{CI}$ \\
\hline \multirow[t]{4}{*}{ Matched controls } & 0 & referent & & & \\
\hline & 0.5 & $0.70^{* a}$ & $(0.11-1.29)$ & & \\
\hline & 1.0 & $1.69^{* b}$ & $(0.58-2.80)$ & & \\
\hline & 2.0 & $2.31^{\mathrm{b} *}$ & $(1.11-3.51)$ & & \\
\hline \multirow[t]{4}{*}{ Arsenic-induced Bowen's disease patients } & 0 & $2.31^{* c}$ & $(0.68-3.94)$ & referent & \\
\hline & 0.5 & $3.53^{*}$ & $(1.50-5.57)$ & $1.22 * a$ & $(0.32-2.12)$ \\
\hline & 1.0 & $4.86^{*}$ & $(3.78-5.94)$ & $2.55^{* b}$ & $(0.82-4.28)$ \\
\hline & 2.0 & $5.36^{*}$ & $(2.90-7.82)$ & $3.04 * \mathrm{c}$ & $(1.20-4.86)$ \\
\hline
\end{tabular}

\footnotetext{
Estimate of $\triangle$ SCEs after adjustment for age, gender, lifestyle characteristics including cigarette smoking, alcohol drinking, passive smoking and tea drinking, status of major diseases, HBsAg carrier status, and arsenic exposure indices.

${ }^{*} p<0.05$ compared with referent.

a.b,c Changes of SCEs induced by arsenite were not statistically significant between cases and matched controls.
} 
increase in arsenite concentration from 1.0 to 2.0 $\mu \mathrm{M}$ for cases and the decrease in RI resulting from the increase in arsenite concentration from 0 to 0.5 $\mu \mathrm{M}$ for controls. The $\Delta \mathrm{RI}$ at various arsenite concentrations were significantly lower in arsenic-induced Bowen's disease patients than in matched controls. In other words, the decrease in arsenite-induced RI was more striking in skin cancer cases than in controls.

In the analysis of possible risk factors associated with SCEs, HFCs and RI in this study, no statistically significant associations were observed for factors such as arsenic-induced skin lesions, age. gender, cigarette smoking, passive smoking, alcohol drinking, and tea drinking. The SCEs and HFCs were higher in cigarette-smoking controls (SCEs = 7.36, HFCs $=10.36 \%$ ) than in non-smoking controls (SCEs $=6.65, \mathrm{HFCs}=7.07 \%)$; and the RI was lower in cigarette-smoking controls (2.21) than non-smoking controls (2.26). But the associations between cigarette smoking and the cytogenetic changes were not statistically significant. However, GEE models were used to adjust for possible confounding effects of age, gender, life-style characteristics including cigarette smoking, alcohol drinking, and tea drinking, status of major diseases and HBsAg carrier status. The results in multivariate analyses remained the same as those in univariate analyses. The difference in SCEs, HFCs and RI between arsenic-induced Bowen's disease patients and matched controls re- mained after further adjustment for arsenic exposure indices. As shown in Table 7, arsenic-induced Bowen's disease patients had higher multivariate-adjusted spontaneous SCEs than matched controls showing an increase of $2.31(95 \% \mathrm{CI}=0.68-3.94)$ SCEs. The increases in SCEs induced by sodium arsenite were $0.70,1.69$ and 2.31 , respectively, at levels of $0.5,1.0$ and $2.0 \mu \mathrm{M}$ among matched controls after multivariate adjustment. The corresponding figures were $3.53,4.86$ and 5.36 , respectively, among arsenic-induced skin cancer patients. The multivariate-adjusted increases in arsenite-induced SCEs at all treatment levels were slightly greater in cases than in controls, but the difference was not statistically significant. As shown in Table 8 , arsenic-induced Bowen's disease patients had higher multivariate-adjusted spontaneous HFCs than matched controls, showing an increase of $16.30 \%$ $(95 \% \mathrm{CI}=8.81 \%-24.20 \%)$ HFCs. The increases in HFCs induced by sodium arsenite were $2.54 \%, 8.09 \%$ and $11.38 \%$, respectively, at levels of $0.5,1.0$ and $2.0 \mu \mathrm{M}$ among matched controls after multivariate adjustment. The corresponding figures were $19.29 \%$, $27.10 \%$ and $28.05 \%$, respectively, among arsenic-induced Bowen's disease patients. The multivariate-adjusted increases in arsenite-induced HFCs at all treatment levels were also slightly greater in cases than in controls, but the difference was not statistically significant.

Table 8

Multiple regression of HFCs of arsenic-induced Bowen's disease patients and matched controls induced by sodium arsenite in GEE model

\begin{tabular}{|c|c|c|c|c|c|}
\hline Subjects & $\mathrm{NaAsO}_{2}(\mu \mathrm{M})$ & $\Delta \mathrm{HFCs}^{2}$ & $95 \% \mathrm{CI}$ & $\Delta \mathrm{HFCs}^{\prime}$ & $95 \% \mathrm{CI}$ \\
\hline \multirow[t]{4}{*}{ Matched controls } & 0 & referent & & & \\
\hline & 0.5 & $2.54^{\prime \prime}$ & $(-0.55-5.63)$ & & \\
\hline & 1.0 & $8.09 * b$ & $(2.33-13.85)$ & & \\
\hline & 2.0 & $11.38 * \mathfrak{c}$ & $(4.43-18.33)$ & & \\
\hline \multirow[t]{4}{*}{ Arsenic-induced Bowen's disease patients } & 0 & $16.30^{\circ}$ & $(8.81-24.20)$ & referent & \\
\hline & 0.5 & $19.29^{*}$ & $(7.84-30.74)$ & $3.00^{\mathrm{a}}$ & $(-3.96-9.96)$ \\
\hline & 1.0 & $27.10^{*}$ & $(14.89-39.31)$ & $10.80^{*}$ & $(2.50-19.10)$ \\
\hline & 2.0 & $28.05^{*}$ & $(14.57-41.53)$ & $11.75^{*}$ & $(1.06-22.44)$ \\
\hline
\end{tabular}

\footnotetext{
"Estimate of $\triangle \mathrm{HFCs}$ after adjustment for age, gender, lifestyle characteristics including cigarette smoking. alcohol drinking, passive smoking and tea drinking, status of major diseases, HBsAg carrier status, and arsenic exposure indices.

" $p<0.05$ compared with referent.

a,b,c Changes of HFCs induced by arsenite were not statistically significant between cases and matched controls.
} 


\section{Discussion}

Arsenic-induced Bowen's disease was found to be significantly associated with arsenic exposure indices, skin hyperpigmentation and hyperkeratosis, and family history of cancer in this study, the same as reported in our previous reports. These findings suggest that both the environmental exposure to arsenic from drinking artesian well water and the individual susceptibility may be involved in the elevated arsenic-induced Bowen's disease risk among residents in BFD-endemic area. In our previous studies carried out in the same study area, only one-third of residents who had consumed high-arsenic artesian well for more than 25 ycars were affected with skin cancer, and the age at the disease onset varied from less than 20 years to greater than 70 years. These findings suggest that in addition to cumulative arsenic exposure, there may exist some individual susceptibility, either genetic or acquired, to the arsenic-induced skin cancer.

Inconsistent findings were reported in previous studies aimed to examine the associations between spontaneous SCEs and age, gender, cigarette smoking, and alcohol drinking. No statistically significant associations with spontaneous SCEs were observed for age and gender in this study. The results were consistent with those of previous studies $[29,42,43]$. Inconsistent with results of studies which showed significant effects of age and gender on the replication of lymphocytes $[33,42]$, no significant associations with RI were observed for age and gender in this study. The range of age in this study was much less than those in other studies, and the sample size of females may be too small to draw a definite conclusion. There were also no significant associations observed for spontaneous SCEs, HFCs and RI with cigarette smoking and alcohol drinking. Skin hyperpigmentation and hyperkeratosis are indices for long-term arsenic exposure. However, those who had skin hyperpigmentation and hyperkeratosis were found to have similar spontaneous SCEs, HFCs and RI compared with those without the skin lesions. No major risk factors associated with SCEs, HFCs, and RI were observed in this study. However, the adjustment for possible confounding effects of these factors was carried out through multiple regression analysis in this study.
In this study, spontaneous and arsenic-induced SCEs, HFCs, and RI were significantly different between arsenic-induced Bowen's disease patients and matched controls with or without adjustment for age, gender, life-style characteristics, major diseases and HBsAg carrier status through GEE models. Elevated spontaneous SCEs have been observed among subjects exposed to inorganic arsenic compared with unexposed ones [19,29]. Sodium arsenite was found to increase SCEs of cultured lymphocytes in a dose-response pattern in both arsenic-induced Bowen's disease patients and matched controls. Previous in vitro studies on human lymphocytes also showed a similar dose-response relationship between arsenic and SCEs [19,24-26]. Though statistically non-significant, the increase in SCEs and HFCs induced by arsenite were consistently higher in arsenic-induced Bowen's disease patients than in healthy controls. As the numbers of cases and controls were small, it merits further investigation, based on a larger sample size, whether arsenic-induced Bowen's disease patients have a higher susceptibility to arsenic-induced SCEs and HFCs at arsenite treatment levels of $2.0 \mu \mathrm{M}$ or higher. It is also worthwhile to elucidate whether the susceptibility results from cumulative arsenic exposure and/or genetic composition if the susceptibility is identified.

The average spontaneous RI was significantly lower in arsenic-induced Bowen's disease patients than in matched controls, indicating a decreased lymphocyte replication among cases in this study. Similar findings have been reported previously among arsenic-exposed subjects compared with the unexposed [31,33]. Sodium arsenite was found to inhibit PHA-induced lymphocyte replication in a dose-response pattern among both arsenic-induced Bowen's disease patients and matched controls. The decreases in RI induced by arsenite were significantly higher among arsenic-induced Bowen's disease patients than matched controls. Arsenic-induced Bowen's disease patients seem to have a greater susceptibility to arsenic-induced inhibition of lymphocyte proliferation than matched controls. Previous studies have shown that sodium arsenite and arsenate inhibit the synthesis of DNA [35]. PHA was found to stimulate $\left[{ }^{3} \mathrm{H}\right]$ thymidine incorporation in mononuclear cells of non-arsenical skin cancer patients, but not of arsenic-induced skin cancer patients 
[44]. Langerhans cells were considered to have an immune response to tumor-associated antigens, and a significant reduction in Langerhans cells was observed in the arsenic-induced Bowen's disease lesions as compared with the adjacent non-tumor skin tissue [44]. The delay in lymphocyte proliferation may indicate the impairment of the cellular immunity. Our findings suggest that long-term arsenic exposure may reduce the immunity of exposed subjects.

Previous in vitro study has shown a $69 \%$ reduction of RI after treatment with $0.1 \mu \mathrm{M}$ arsenite [34], but the reductions in RI after treatment with $2 \mu \mathrm{M}$ arsenite were only $13 \%$ and $6 \%$, respectively, among arsenic-induced Bowen's disease patients and matched controls in this study. Whether the long-term exposure to arsenic may result in a resistance to arsenic-induced inhibition of lymphocyte proliferation. and the resistance is greater in matched controls than arsenic-induced Bowen's disease patients, merits further investigation.

Most study subjects had stopped drinking high-arsenic artesian well water for more than 20 years. Arsenic-induced skin cancers still occur among subjects who have been exposed to ingested inorganic arsenic for a long period of time. The cytogenetic damages and delayed cell proliferations observed in this study were greater among cases than matched controls. The case-control difference may be due to the higher cumulative arsenic exposure in cases than in controls. It may also involve some other factors such as individual susceptibility, nutritional status and genetic predisposition. Further investigations are needed to differentiate the independent and interactive effects of environmental and hereditary components on cytogenetic damage among residents in the arseniasis-hyperendemic villages.

\section{Acknowledgements}

Supported by grants from the National Science Council and Department of Health. Executive Yuan, Republic of China (NSC-80-0412-B002-17, NSC-810412-B002-122, NSC-82-0412-B002-262, NSC-830412-B002-231, NSC-84-2331-B002-199, DOH85HR-503).

\section{References}

[1] IARC (1980) IARC monographs on the evaluation of the carcinogenic risk of chemicals to man: some metals and metallic compunds, Vol. 23, International Agency for Research on Cancer, Lyon.

[2] IARC (1987) IARC monographs on the evaluation of carcinogenic risk to humans overall evaluations of carcinogenicity: an updating of IARC monographs Vol. 1-42, suppl 7. International Agency for Research on Cancer, Lyon.

[3] W.P. Tseng, H.M. Chu, S.W. How, J.W. Fong, C.S. Lin, S. Yel, Prevalence of skin cancer in an endemic area of chronic arsenicism in Taiwan. J. Natl. Cancer Inst. 40 (1968) 453463.

[4] M.E. Cebrian, A. Albores, M. Aguliar, E. Blakerly, Chronic arsenic poisoning in the north of Mexico, Human Toxicol. 2 (1983) $121-133$.

[5] J.M. Borgono, P. Vincent, H. Venturino, A. Infante, Arsenic in the drinking water of the city of Antofagasta: epidemiological and clinical study before and after installation of a treatment plant, Environ. Health Perspect. 19 (1977) 103105.

[6] R.E. Biagini, G.C. Quiroga, V. Elias, Chronic hydroarsenic in Ururan, Arch. Argentin. Dermatol. 24 (1974) 8-1!.

[7] Dora. C.F. (1995) Human exposure and health effects of arsenc in drinking water in Hungary and Romania. Presented in SEGH Second International Conference on Arsenic Exposure and Health Effects, San Diego, CA

[8] Y.Z. Huang, X.C. Qian, G.Q. Wang. Chronic arsenism in Xinjiang, Chinese Med. J. 98 (1985) 219.

[9] Luo, Z.D. and Y.M. Zhang (1995) Chronic arsenism and cancer in inner mongolla-consequences of arsenic in deep wells. Presented in SEGH Second International Conference on Arsenic Exposure and Health Effects. San Diego. California.

[10] D. Das, A. Chatterjee, B.K. Mandal, G. Samanta, D. Chakraborti, B. Chanda, Arsenic in ground water in six districts of West Bengal, India: the biggest arsenic calamity in the world. Part 2. Arsenic concentration in drinking water. hair, nails. urine. skin-scale and liver tissue (biopsy) of the affected people. Analyst 120 (1995) 917-924.

[11] Choprapawon, C. (1995) Chronic arsenic posioning in Ronpibeel District. Nakorn Srithammarat Province, Southern Thailand. Presented in SEGH Second International Conference on Arsenic Exposure and Health Effects, San Diego, California.

[12] C.J. Chen. T.C. Chuang, T.M. Lin. H.Y. Wu. Malignant neoplasms among residents of a blackfoot disease-endemic area in Taiwan: high-arsenic artesian well water and cancers. Cancer Res. 45 (1985) 5895-5899.

[13] C.J. Chen, Y.C. Chuang, S.L. You, T.M. Lin, H.Y. Wu, A retrospective study on malignant neoplasms of bladder, lung and liver in blackfoot disease endemic area in Taiwan. Br. $\mathbf{J}$. Cancer 53 ( 1986) 399-405.

[14] C.J. Chen, T.L. Kuo, M.M. Wu, Arsenic and cancers. Lancet 2 (1988) 414-415.

[15] C.J. Chen, C.J. Wang, Ecological correlation between arsenic 
level in well water and age-adjusted mortality from malignant neoplasms, Cancer Res. 50 (1990) 5470-5474.

[16] C.J. Chen, C.W. Chen, M.M. Wu, T.L. Kuo, Cancer potonrial in liver, lung, bladder and kidney due to ingested inorganic arsenic in drinking water, Br. J. Cancer 66 (1992) 888-892.

[17] H.Y. Chiou, Y.M. Hsueh, K.F. Liaw, S.F. Ilorng, M.H. Chiang. Y.S. Pu, J.S. Lin, C.H. Huang, C.J. Chen, Incidence of internal cancers and ingested inorganic arsenic: a sevenyears follow up study in Taiwan, Cancer Res. 55 (1995) $1296-1330$.

[18] Y.M. Hsueh, G.S. Cheng, M.M. Wu, H.S. Yu, T.L. Kuo. C.J. Chen, Multiple risk factors associatiated with arsenic induced skin cancer: effects of chronic liver disease and malnutritional status, Br. J. Cancer 71 (1995) 109-114.

[19] W.N. Wen, T.L. Lieu, H.J. Chang, S.W. Wuu. M.L. Yau, K.Y. Jan, Baseline and sodium arsenite-induced sister chromatid exchanges in cultured lymphocytes from patients with blackfoot disease and healthy persons, Hum. Genet, 59 (1981) 201-203.

[20] B. Wan, R.T. Christian, S.W. Soukup, Studies of cytogenetic effects of sodiun arsenicals on mammalian cell in vitro. Environ. Mutagen. 4 (1982) 493-498.

[21] T.C. Lee, M. Oshimura, J.C. Barrett, Comparison of arsenicinduced cell transformation, cytotoxicity, mutation and cytogenetic effect in Syrian hamster cmbryo cells in culture, Carcinogenesis 6 (1985) 1421-1426.

[22] T.C. Lee, R.Y. Huang, K.Y. Jan, Sodium arsenite enhances the cytotoxicity, clastogenicity, and 6-thioguanine-resistant mutagenicity of ultraviolet light in Chinese hamster ovary cells, Mutation Res. 148 (1985) 83-89.

[23] T.C. Lee, K.C. Lee, Y.J. Tzeng, R.Y. Huang, K.Y. Jan, Sodium arsenite potentiates the clastogenicity and mutagenicity of DNA crosslinking agents, Environ. Mutagen. 8 (1986) $119-128$.

[24] A.N. Jha, M. Noditi, R. Nilsson, A.T. Natarajan, Genotoxic effects of sodium arsenite on human cells. Mutation Res. 284 (1992) 215-221.

[25] J.K. Wiencke, J.W. Yager, Specificity of arsenite in potentiating cytogenetic damage induced by the DNA crosslinking agent diepoxybutane. Environ. Mol. Mut. 19 (1992) 195-200.

[26] A. Hartmann. G. Speit. Comparative investigations of the genotoxic effects of metals in the single cell gel (SCG) assay and the sister chromatid exchange (SCE) test, Environ. Mol. Mut. 23 (1994) 299-305.

[27] M.L. Larramendy, N.C. Popescu, J. Dipaolo, Induction by inorganic metal salts of sister chromatid exchanges and chromosome aberrations in human and Syrian hamster strain, Environ. Mutagen. 3 (1981) 597-606.

[28] K. Nakamuro, Y.C. Sayato, Comparative studies of the chromosomal aberrations induced by trivalent and pentavalent arsenic, Mutation Res. 88 (1981) 73-80.

[29] D. Lerda, Sister-chromatid exchange (SCF) among individuals chronically exposed to arsenic in drinking water. Mutation Res. 312 (1994) 111-120.

[30] B.K. Vig. M.L. Figueroa, M.N. Cornforth, S.II. Jenkins,
Chromosome studies in human subjects chronically exposed to arsenic in drinking water, Am. J. Ind. Med. 6 (1984) $325-338$.

[31] P. Ostrosky-Wegman. M.E. Gonsebatt, R. Montero, L. Vega, H. Barba, J. Espinosa, A. Palao, C. Cortinas, G. GarciaVargas, L.M. Razo, M. Cebrian, Lymphocyte proliferation kinctics and genotoxic findings in a pilot study on individuals chronically exposured to arsenic in Mexico, Mutation Res. 250 (1991) 477-482.

[32] Stoll, H.L. and R.A. Schwartz (1992) Squamous cell carcinoma, In: T. Fitzpatrick, A. Eiaen, K. Wolff, I. Freedberg, K.F. Austen (Eds.), Dermatology in General Medicine, McGraw-Hill, New York, pp. 746-758.

[33] M.E. Gonsebatt, L. Vega. R. Montero, G. Garciel. A. Albores, M.E. Cebrian, P. Ostrosky-Wegman. Lyphocyte replicating ability in individuals exposed to arsenic via drinking water. Mutation Res. 313 (1994) 293-299.

[34] M.E. Gonsebat, L. Vega, L.A. Herrera, R. Mortero, E. Rojas, M.E. Cebrian, P. Ostrosky-Wegman, Inorganic arsenic effects on human lymphocyte stimulation and proliferation, Mutation Res. 283 (1992) 91-95.

[35] Meng, Z. (1994) Effects of arsenic on DNA synthesis in human lymphocytes. In: J.O. Nriagu (Ed.). Arsenic in the Environment. Part I: Human Health and Ecosystem Effects, John Wiley and Sons Inc., New York. pp. 133-142.

[36] Kuo T.L. (1964) Arsenic content of artesian well water in endemic area of chronic arsenic poisoning. Report. Institute of Pathology. National Tiawan University, no. 20, pp. 7-13

[37] S. Yeh, Skin cancer in chronic arsenicism, Hum. Pathol. 4 (1973) 469-485.

[38] Lo. M.C., Y.C. Hsen and B.K. Lin (1977) Arsenic content of underground water in Taiwan: second report. Taiwan Provincial Institute of Environment Sanitation: Taichung, Taiwan.

[39] P. Perry, S. Wolff, New giemsa method for the differential staining of sister-chromatids, Nature 251 (1974) 156-158.

[40] Moore, D.H. and A.V. Carrano (1984) Statistical analysis of high SCE frequency cells in human lymphocytes, In: R.R. Tice and A. Hollaender (Eds.), Basic Life Sciences, Vol. 29, Plenum, New York, pp. 469-479.

[41] S.L. Zeger. K.Y. Liang, The analysis of distrete and continuous longitudinal data, Biometrics 42 (1988) 121-130.

[42] D. Anderson. A.J. Francis, P. Godbert. P.C. Jenkinson. K.R. Butterworth. Chromosome aberration (CA). sister-chromatid exchanges ( $\mathrm{SCE}$ ) and mitogen induced blastogenesis in culturcd peripheral lymphocytes from 48 control individuals sampled 8 times over 2 years, Mutation Res. 250 (1991) $467-476$.

[43] D. Anderson, A.J. Francis, P. Godbert, P.C. Jenkinson, K.K. Butterworth, Variability in chromosome aberrations, sister chromatid exchanges, and mitogen-induced blastogenesis in peripheral lymphocytes from control individuals, Environ. Health Persp. Supplements 101 (suppl. 3) (1993) 83-88.

[44] H.S. Yu, K.L. Chang, C.M. Wang, C.L. Yu, Alterations of mitogenic responses of mononuclear cells by arsenic in arsenical skin cancers, J. Dermatol. 19 (1992) 710-714. 